\title{
Molecular identification of Cryptosporidium spp. from animal sources in China
}

\author{
Jianhai Yin, Zhongying Yuan, Yujuan Shen, Jing Zhang, Yanyan Jiang, Jianping Cao \\ National Institute of Parasitic Diseases, Chinese Center for Disease Control and Prevention ; Laboratory of \\ Parasite and Vector Biology, $\mathrm{MOH}$, China ; WHO Collaborating Center for Malaria, Schistosomiasis and \\ Filariasis, Shanghai 200025, PR China
}

Key words: Cryptosporidium; pet animals; China

J Infect Dev Ctries 2013; 7(12):1020-1022. doi:10.3855/jidc.3540

(Received 13 March 2013- Accepted 23 August 2013)

Copyright (C) 2013 Yin et al. This is an open-access article distributed under the Creative Commons Attribution License, which permits unrestricted use, distribution, and reproduction in any medium, provided the original work is properly cited.

\section{Introduction}

Cryptosporidium spp. causes the diarrheal illness called cryptosporidiosis that may be fatal in the immunocompromised. More attention has been focused on the epidemiology and detection of Cryptosporidium in China including studies on infection in humans, animal populations and environmental water. Cryptosporidium has been an essential indicator in Standards for Drinking Water Quality (GB5749-2006) in China from 1 July 2008.

Domestic animals play an active role in family life, particularly dogs and cats involving continuous close contact with humans. In China, it was reported that the cities of Shanghai, Beijing, Guangzhou, Chongqing and Wuhan have been recognized as 'Pet City', and it was estimated that there are at least 150 million pet dogs around the country [1]. It is important to raise awareness that domestic animals may harbor zoonotic parasites such as Cryptosporidium asymptomatically. Infection of Cryptosporidium in dogs and cats has been reported in some countries, including the hostadapted and zoonotic Cryptosporidium canis infected in dogs from Japan [2] and Canada [3], Cryptosporidium parvum in dogs from Germany [4] and Costa Rica [5], and in cats from other countries [4, 5]. The host-adapted and zoonotic Cryptosporidium felis has been reported in cats from USA [6] as well as a report of a mixed infection in a cat involving Cryptosporidium muris and Cryptosporidium felis [7]. However, little relative information is known about the prevalence of Cryptosporidium in domestic animals in China. This study was aimed to estimate the prevalence of Cryptosporidium among the pet dogs and cats and other animals in a zoo of Shanghai, China.

\section{The Study}

Eighty-four fecal samples were collected from 19 caged dogs, 11 kennel cats from a pet hospital and 54 other animals (Table 1), as well as 8 wastewater samples from drainage channels from a zoo. Genomic DNA was extracted from feces using the QIAamp DNA Stool Mini Kit (Qiagen, Valencia, USA) following the manufacturer's instruction of Protocol, and DNA was stored at $-20^{\circ} \mathrm{C}$ before it was used in PCR amplification reactions. Nested PCR was used to amplify an approximately 840 base pair (bp) long fragment of the SSU rRNA gene using two sets of oligonucleotide primers: F1: TTCTAGAGCTAATACATGCG and R1: CCCATTTCCTTCGAAACAGGA for primary PCR and F2: GGAAGGGTTGTATTTATTAGATAAAG and R2: CTCATAAGGTGCTGAAGGAGTAfor secondary PCR[8]. Amplification reactions were carried out in $25 \mu \mathrm{l}$ volumes consisting of $12.5 \mu \mathrm{l} \mathrm{Taq}$ Green Master Mix (2X), $1 \mu 1$ of each primer (10X), $9.5 \mu 1$ nuclease-free water and $1 \mu 1$ DNA. Reaction conditions were comprised of a hot start at $94^{\circ} \mathrm{C}$ for 1 min followed by 35 cycles at $94^{\circ} \mathrm{C}$ for $10 \mathrm{~s}, 55^{\circ} \mathrm{C}$ for $30 \mathrm{~s}$ and $72^{\circ} \mathrm{C}$ for $1 \mathrm{~min}$ and a final extension at $72^{\circ} \mathrm{C}$ for $10 \mathrm{~min}$. 
Table 1: The list of animals and Cryptosporidium spp. infection in this study

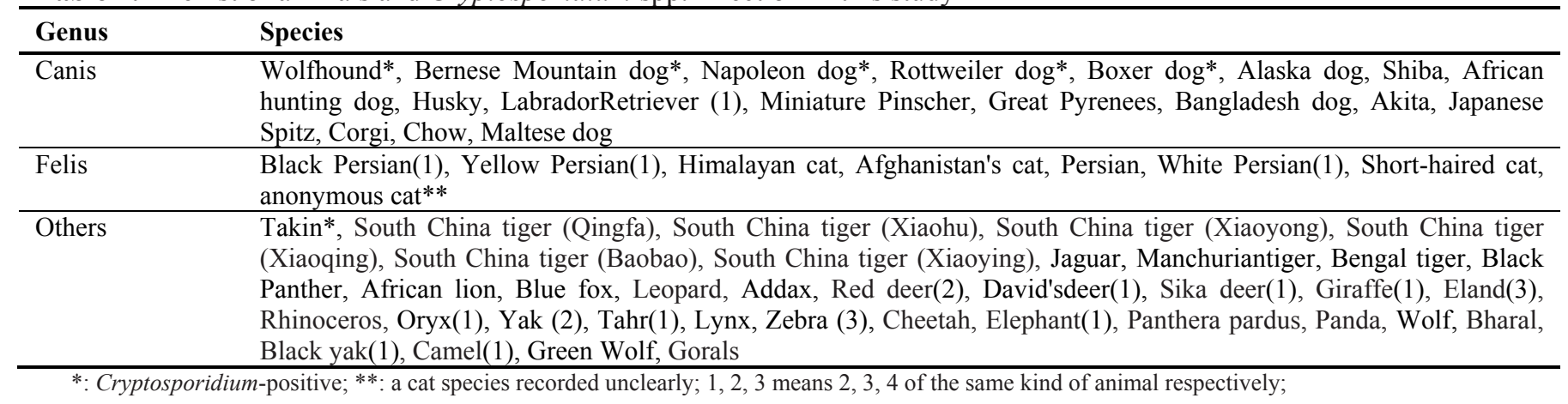

Amplified regions were separated by $2 \%$ agarose gel electrophoresis and visualized following ethidium bromide staining. Amplified secondary PCR products were subjected to two directional sequencing with secondary primers by Invitrogen Ltd. (Shanghai). Sequences were blasted against sequences present in the NCBI database (http://blast.ncbi.nlm.nih.gov/) and multiple alignments were carried out using ClustalX 1.83. Phylogenetic relationship analyses were performed using MEGA 4.1 software.

A total of six Cryptosporidium positive samples with a infection rate of 7\% (6/84) were detected from a Wolfhound, a Bernese Mountain dog, a Napoleon dog, a Rottweiler dog, a Boxer dog and a takin. No Cryptosporidium positive feces were detected from cats. There were some base substitutions found through multiplex alignments against each other and reference data. And the phylogenetic analysis turned out that the isolates from Wolfhound, Bernese Mountain dog, Napoleon dog, Rottweiler dog, and Boxer dog were belonged to Cryptosporidium canis, and the takin's isolate was Cryptosporidium andersoni. The nucleotide sequences in this study deposited in GenBank under accession numbers KF516539-KF516544.

Cryptosporidium canis has been found in human and considered as a zoonotic pathogen [9]. Xiao et al firstly reported the possible transmission of cryptosporidiosis between humans and dogs in a longitudinal cohort diarrhea study in Lima, Peru [10]. In Shanghai, infection with $C$. canis has also been reported in children from two pediatric hospitals [11]. Likewise, dogs can be the host of other types of Cryptosporidium, such as isolation of C. muris in a Texas canine population [12], although no positive was found in the present study, more attention should also be caused, and further works should be carried out to understand the real prevalence of this parasite or others infected in dogs.

Cryptosporidium andersoni is considered as a main type of Cryptosporidium in the bovine also has been isolated from humans. Furthermore, $C$. andersoni is recognized as one of the most common opportunistic and non-opportunistic pathogens HIV/AIDS patient with chronic diarrhea [13]. In China, $C$. andersoni was the dominant species in cattle [14]. And we have isolated this species from adult diarrhea patients from one Shanghai hospital (unpublished). It was also identified from diarrheal patients in others' study [15].

Fortunately, all the samples from cats and wastewater in the study were negative of Cryptosporidium spp., but the zoonotic species such as $C$. parvum and $C$. felis have been found in some studies $[5,16]$, and in addition, more and more studies were involved in the water quality with this parasite including China, and different species and genotypes have been identified [17-19].

Consequently, the present work suggested that the infection of Cryptosporidium in pet dogs and other animals poses a significant potential public health threat and that surveillance practices must be established to prevent zoonotic disease of humans as well as pay more attention to the improvement of the management of animals.

\section{Acknowledgements}

This work was supported by grants from the National S \& T Major Program of China (No. 2009ZX10004-201, No. 2012ZX10004-201) and Shanghai Public Health Outstanding Academic Leader (No. GWDTR201214).

\section{References}

1. Wu Y, Wang J, Song Q, Meng F, Ba X, Liu W (2007) A survey of the current status of pet market in Wuhan. China Animal Husbandry \& Veterinary Medicine 11: 145-147. 
2. Satoh M, Matsubara-Nihei Y, Sasaki T, Nakai Y (2006) Characterization of Cryptosporidium canisisolated in Japan. ParasitolRes 99: 746-748.

3. Uehlinger FD, Greenwood SJ, McClure JT, Conboy G, O'Handley R, Barkema HW (2013) Zoonotic potential of Giardia duodenalis and Cryptosporidium spp. and prevalence of intestinal parasites in young dogs from different populations on Prince Edward Island, Canada.Vet Parasitol. doi: 10.1016 .

4. Sotiriadou I, Pantchev N, Gassmann D, Karanis P (2013) Molecular identification of Giardia and Cryptosporidium from dogsand cats.Parasite20:8.

5. Scorza AV, Duncan C, Miles L, Lappin MR (2011) Prevalence of selected zoonotic and vector-borne agents in dogsand cats in Costa Rica.Vet Parasitol 183: 178-183.

6. Ballweber LR, Panuska C, Huston CL, Vasilopulos R, Pharr GT, Mackin A (2009) Prevalence of and risk factors associated with shedding of Cryptosporidium felis in domestic cats of Mississippi and Alabama. Vet Parasitol 160: 306-310.

7. FitzGerald L, Bennett M, Ng J, Nicholls P, James F, Elliot A, Slaven M, Ryan U (2011) Morphological and molecular characterisation of mixedCryptosporidium muris/Cryptosporidium felis infection in a cat.Vet Parasitol 175: 160-164.

8. Jiang J, Alderisio KA, Xiao L (2005) Distribution of Cryptosporidium genotypes in storm event water samples from three watersheds in New York. ApplEnvironMicrobiol 71: 4446-4454.

9. Xiao L (2010) Molecular epidemiology of cryptosporidiosis: an update. ExpParasitol 124: 80-89.

10. Xiao L, Cama VA, Cabrera L, Ortega Y, Pearson J, Gilman RH (2007) Possible transmission of Cryptosporidium canis among children and a dog in a household. J ClinMicrobiol 45: 2014-2016.

11. Feng Y, Wang L, Duan L, Gomez-Puerta LA, Zhang L, Zhao X, Hu J, Zhang N, Xiao L (2012) Extended outbreak of cryptosporidiosis in a pediatric hospital, China.Emerg Infect Dis 18: 312-314.

12. Lupo PJ, Langer-Curry RC, Robinson M, Okhuysen PC, Chappell CL (2008) Cryptosporidiummuris in a Texas canine population. Am J Trop Med Hyg78: 917-921.

13. Agholi M, Hatam GR, Motazedian MH (2013) HIV/AIDSassociated opportunistic protozoaldiarrhea.AIDS Res Hum Retroviruses 29: 35-41.
14. Zhang W, Wang R, Yang F, Zhang L, Cao J, Zhang X, Ling H, Liu A, Shen Y (2013) Distribution and Genetic Characterizations of Cryptosporidium spp. in Pre-Weaned Dairy Calves in Northeastern China's Heilongjiang Province.PLoS One8:e54857.

15. Leoni F, Amar C, Nichols G, Pedraza-Diaz S, McLauchlin J (2006) Genetic analysis of Cryptosporidium from 2414 humans with diarrhoea in England between 1985 and 2000. J Med Microbiol 55: 703-707.

16. Sotiriadou I, Pantchev N, Gassmann D, Karanis P (2013) Molecular identification of Giardia and Cryptosporidium from dogs and cats.Parasite20:8.

17. Xiao G, Qiu Z, Qi J, Chen JA, Liu F, Liu W, Luo J, Shu W (2013) Occurrence and potential health risk of Cryptosporidium and Giardia in the Three Gorges Reservoir, China.Water Resdoi: 10.1016.

18. Xiao S, An W, Chen Z, Zhang D, Yu J, Yang M (2012) The burden of drinking water-associated cryptosporidiosis in China: the large contribution of the immunodeficient population identified by quantitative microbial risk assessment.Water Res 46: 4272-4280.

19. Feng Y, Zhao X, Chen J, Jin W, Zhou X, Li N, Wang L, Xiao L (2011) Occurrence, source, and human infection potential of Cryptosporidium and Giardia spp. in source and tap water in Shanghai, China.Appl Environ Microbiol 77: 3609-3616.

\section{Corresponding author}

Dr. Jianping Cao

NIPD, China CDC

Laboratory of Parasite and Vector Biology, MOH, China

WHO Collaborating Center for Malaria,Schistosomiasis and

Filariasis

Shanghai 200025, PR China

Telephone: +86-21-64735258

Fax: +86-21-64332670.

Email: caojp@yahoo.com

Conflict of interests: No conflict of interests is declared. 